\title{
APLICAÇÃO DA TEORIA DAS OPÇÕES REAIS NA AVALIAÇÃO DE UM PROJETO DE MINERAÇÃO.
}

\author{
Ricardo Bordeaux-Rêgo ${ }^{1}$ \\ Carlos Eduardo Ribeiro Flora da Silva ${ }^{2}$ \\ Daniel Hermsdorff Vellozo Gaichi ${ }^{3}$ \\ Wilson Lapa Santos Junior ${ }^{4}$
}

\begin{abstract}
Resumo: Este trabalho objetiva apresentar e discutir a Teoria de Opções Reais (TOR) e compará-la com modelos tradicionais utilizados em instituições financeiras - o método de avaliação pelo Valor Presente Líquido (VPL) e a Taxa Interna de Retorno (TIR). São consideradas premissas sobre a situação da economia e do mercado avaliando um projeto de minério de ferro por meio de uma análise de sensibilidade com os principais direcionadores. O resultado apresenta um modelo de avaliação que considere as flexibilidades, e a capacidade de o projeto se adaptar ao longo do tempo, devido a certos fatores, o que torne a análise mais realista e menos simplificada do que a visão pelo VPL e TIR.
\end{abstract}

Palavras-Chave: Teoria das Opções Reais (TOR); Avaliação de Projetos, Árvore de Decisão.

Abstract: This paper aims to present and discuss the Theory of Real Options (ROA) and compare it with traditional models used in financial institutions - the valuation at Net Present Value (NPV) and Internal Rate of Return (IRR). Assumptions are considered about the state of the economy and market, evaluating a project of iron ore through a sensitivity analysis with key drivers. The result presents an evaluation model that considers the flexibility, and the ability of the project to adapt over time, due to certain factors, which make the analysis more realistic and less streamlined than the vision by NPV and IRR.

Key-words: Real Options Analysis (ROA), Project Evaluation, Decision Tree.

\footnotetext{
${ }^{1}$ Dept $^{\circ}$ de Engenharia de Produção- UFF- Campus Niterói. E-mail : ribordeaux@ hotmail.com

${ }^{2}$ Dept $^{\mathbf{o}}$ de Engenharia de Produção- UFF-Campus Niterói E-mail : cadu.flora@gmail.com

${ }^{3}$ Engenharia de Produção- UFF- Campus Niterói E-mail :

${ }^{4}$ Dept $^{\mathrm{o}}$ de Engenharia de Produção- UFF- Campus Niterói E-mail : wilsonlapasantos@gmail.com
} 


\section{Introdução}

A avaliação de empresas é atualmente um dos temas mais importantes e interessantes dentro da área financeira. Desempenha um papel chave em muitas áreas financeiras, em fusões e aquisições e na gestão de carteiras de investimento, segundo Damodaran (2003). Com o colapso da bolha imobiliária norte-americana, deflagrando a crise econômica de 2008, e a desaceleração nas economias norteamericana e europeia, muito se tem questionado os métodos de avaliação envolvidos não só para empresas do ramo imobiliário, como para as empresas em geral.

Segundo Damodaran (2003), o valor de uma empresa pode ser diretamente relacionado às decisões que toma, de modo que as escolhas realizadas implicarão direta e indiretamente na maximização do lucro e cumprimento ou não de suas metas.

A intenção de se avaliar as empresas é alcançar o seu preço justo em determinado momento, tendo em vista todo o potencial de gerar receitas e despesas. Dessa forma, tais avaliações poderão facilitar o processo decisório da realização de determinado investimento, buscando gerar valor para empresa e a manutenção da existência desta.

Pesquisa feita por Graham e Harvey (2001) aponta o método do Valor Presente Líquido (VPL) como a técnica mais requisitada pelos profissionais e executivos que avaliam investimentos. Já o trabalho de Vale (2012), que replicou a metodologia de Graham e Harvey no Brasil por meio de uma pesquisa com diretores financeiros, aponta a taxa interna de retorno em primeiro lugar com $81 \%$ das respostas, seguida pelo VPL com $76 \%$.

O modelo VPL, também denominado fluxo de caixa descontado, utiliza como taxa de desconto o custo médio ponderado de capital (WACC sigla em inglês), levando em conta as proporções de capital próprio e dívida, bem como respectivos custos e benefício fiscal. Damodaram (2003) afirma que o fluxo de caixa descontado relaciona o valor de ativo ao valor presente dos fluxos de caixa futuros esperados relativos àquele ativo.

Conforme Copeland et al (2001), o VPL é o fundamento da análise de opções reais, mas este pressupõe implicitamente que não há flexibilidade na tomada de decisões, enquanto a Teoria das Opções Reais (TOR ou ROA, em inglês - Real Options Analysis) modela a flexibilidade da tomada de decisões. De fato, durante a vida útil de projetos, decisões podem ser tomadas no sentido de, por exemplo, adiar ou antecipar investimentos, contrair ou expandir, abortar o projeto, entre outras. Cada decisão dessas é opção que o gestor possui, o direito mas não a obrigação de exercer.

A TOR pode ser vista como extensão das opções financeiras, com aplicação na avaliação de investimentos. De acordo com Copeland et al (2003), essa forma de avaliação de ativos é mais interessante para mensurar as flexibilidades possíveis que o projeto possa apresentar, já que trabalha com uma maior precisão e capacitação para se adaptar diante novas informações.

O objetivo deste estudo é a Aplicação da TOR na avaliação de um projeto de minério de ferro, com flexibilidades gerenciais, em um ambiente de incertezas em uma empresa de mineração e determinar o valor do mesmo. Pode-se afirmar que os fluxos de caixa gerados pelo preço do minério de ferro e seus custos associados são incertos e neste setor, teoricamente, caso o preço do minério de ferro esteja abaixo do seu custo operacional, a mina pode ser desligada temporariamente, o que mostra uma flexibilização do projeto.

Para dar embasamento à pesquisa, foi realizada uma revisão de literatura relevante sobre o tema e análise crítica dos trabalhos selecionados. Posteriormente, a metodologia de estudo de caso foi escolhida para confrontar a teoria com a prática, identificando pontos 
fortes e limitações na utilização da metodologia TOR.

\section{Opções Reais}

Assume-se como premissa que nas empresas alinham-se objetivos individuais de maneira a se obter resultantes próximas da maximização da riqueza de acionistas. Dada essa premissa, diversos modelos de avaliação econômica procuram quantificar $\mathrm{o}$ retorno gerado pelas organizações e projetos. Os já citados VPL e TIR, apesar da popularidade, têm despertado críticas ao uso estático. De fato, essas técnicas são fundamentadas apenas no retorno financeiro gerado. Utilizam estritamente fatores tangíveis e não levam em consideração fatores tais como imagem, propriedade intelectual, entre outros.

Dessa forma, ao condicionar a atratividade de um projeto apenas ao resultado do VPL presume-se a total passividade da gerência ao longo do projeto e estrito comprometimento com a estratégia determinada no momento da avaliação. Na prática, os gestores alteram o curso previamente definido de acordo com a dinâmica dos fatores externos, sempre com o objetivo de reduzir possíveis perdas ou beneficiarem-se das oportunidades disponíveis no momento.

Segundo Minardi (2000) a teoria de opções se apresenta como abordagem superior para integrar estratégia e finanças, pois considera, analiticamente, as opções de crescimento e as flexibilidades gerenciais, ou as formas de adaptação às mudanças do ambiente empresarial.

O trabalho de Braga et al (2009) aplicou a TOR no Brasil, em estudo de viabilidade econômica da integração de células a combustível nas plantas de cloro-soda. Foram utilizados como parâmetros o custo do investimento, a volatilidade a taxa de juros livre de risco e taxa de dividendos. Os resultados apontaram que a viabilidade do empreendimento dependia de ação governamental.
Copeland et al (2003), argumentam a favor da utilização do modelo das opções reais, visto que este captura as flexibilidades disponíveis aos tomadores de decisão como, por exemplo, postergar o investimento, contrair ou expandir a escala de produção, abandonar temporária ou definitivamente e investir em projetos dependentes deste primeiro. A aplicação do modelo pode ser resumida da seguinte forma:

1. Calcular o VPL do projeto ao longo de sua vida útil sem a interferência de Opções Reais.

2. Construir uma árvore de decisão, baseada em premissas de volatilidade do projeto.

3. Definir os marcos dentro da árvore de eventos para transformá-la em uma árvore de decisão. Tais dados serão as decisões gerenciais que a empresa irá apresentar para o projeto.

4. Avaliar os resultados gerados pela árvore de decisão comparada com o valor obtido pelo passo um, ou seja, o modelo sem nenhuma flexibilização.

\section{1 Árvore de decisão}

A árvore de decisão é uma representação gráfica que auxilia a tomada de decisão sob a incerteza. Segundo Minardi (2000) a árvore de decisão procura antecipar as ações gerenciais que ocorrerão em virtude das mudanças das condições de mercado. $\mathrm{O}$ valor presente líquido é função não apenas das condições de mercado esperadas no início do projeto, mas também das futuras ações gerenciais. A cada momento, cada ramo da árvore corresponde a uma decisão, conforme os cenários de mercado. A probabilidade atribuída a cada ramo é subjetiva, tendo cada ramo risco diferente e, portanto, devendo-se ter taxa de desconto diferente, o que torna a implementação, a risca do modelo, bastante complexa.

Segundo Nepomuceno (1997) o uso da árvore de decisão enriquece a tomada de decisão pelo fornecimento de uma 
analise lógica e sistemática. $\mathrm{O}$ método pode ser sumariado da seguinte forma:

Definir que possíveis resultados poderão ocorrer para cada uma das escolhas de decisão disponíveis ou alternativas;

- Avaliar o resultado de cada opção e seu respectivo VPL;

- Determinar ou estimar a probabilidade de ocorrência de cada possível resultado;

- Calcular o valor esperado de cada decisão, sendo este a média ponderada do VPL das alternativas disponíveis.

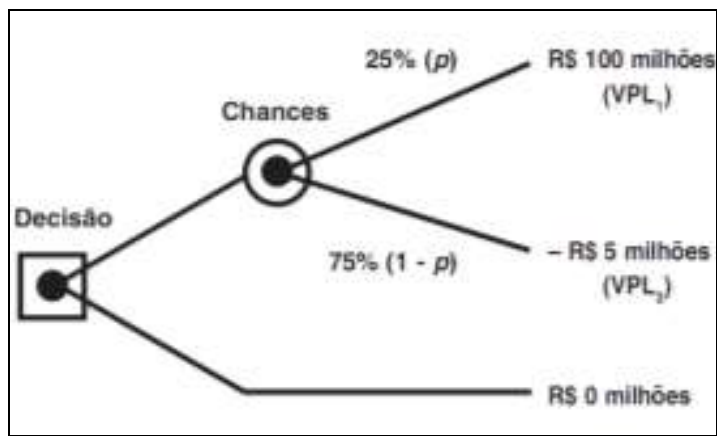

Figura 1 - Árvore de decisão simplificada com dois possíveis resultados

$\mathrm{Na}$ figura 1 , o quadrado representa uma decisão, o círculo representa as alternativas de resultados do projeto e p é a probabilidade de sucesso do projeto. $\mathrm{O}$ valor monetário esperado calculado para o projeto da Figura 1 é R \$21,25 milhões segundo seguinte equação:

Equação 1 - Valor Monetário Esperado (VME)

$\mathrm{VME}=\mathrm{p} \times \mathrm{VPL}_{1}+(1-\mathrm{p}) \times \mathrm{VPL}_{2}$

Brandão e Dyer (2005) sugerem primeiramente o cálculo do valor presente líquido sem flexibilidade. A seguir, utiliza-se o modelo binomial computacional para modelar o ativo básico e procede-se a modelagem das opções reais no projeto. Finalmente, ocorre a resolução da árvore binomial, que é a análise das opções reais.

Trigeorgis (1993) define a aditividade dos valores das diversas opções reais. Desse modo, ao se considerarem várias flexibilidades diferentes, o valor de cada opção pode ser adicionado aos de outras.

O método das opções reais pode ser aplicado em setores bem diferentes, tais como na avaliação de terrenos, como aponta o trabalho de Womack (2012) e no estudo de parcerias público privadas no Brasil, de Brandão et. Al. (2012).

O método das opções reais apresenta, entretanto, limitações como a dependência da estimação do comportamento das principais variáveis. Depende também da sensibilidade dos avaliadores para com o fenômeno estudado. Pode-se exemplificar com a estimação da volatilidade do comportamento de variáveis como preços, volumes, vendas, entre outras.

\section{OBJETO DO ESTUDO: O SETOR DE MINERAÇÃO}

\subsection{Oferta Mundial}

As reservas mundiais comprovadas de minério de ferro são da ordem de 170 bilhões de toneladas, destacando-se a Ucrânia, Rússia, China, Austrália, EUA e Brasil, segundo o Sumário Mineral de Commodities do Departamento de Pesquisas Geológicas dos EUA (USGS) de Janeiro de 2012.

Em 2011, a produção mundial de concentrado de ferro foi da ordem de 1,8 bilhão de toneladas, sendo $63 \%$ Fines, $24 \%$ Pellet e $13 \%$ Lump. Os principais produtores do mineral são Austrália (26,7\%), Brasil (18,3\%), China (16,9\%) e Índia $(9,9 \%)$, sendo que a China é o único país acima com produção voltada exclusivamente para o mercado interno, uma vez que os demais são seus principais fornecedores dentro do mercado transoceânico.

As reservas brasileiras, com um teor médio de $56,0 \%$ de ferro, estão localizadas, em sua grande maioria, nos estados de Minas Gerais, Pará e Mato Grosso do Sul. Minas Gerais $(67,0 \%)$ e 
Pará $(29,3 \%)$ foram os principais Estados produtores, de acordo com o Instituto Brasileiro de Mineração (IBRAM).

O principal uso do minério de ferro é na siderurgia, seja diretamente na produção de ferro-gusa ou na redução direta para a produção de ferro-esponja, com isso é de extrema importância avaliar a oferta de aço para melhor entender o mercado de minério de ferro. Para se ter noção da importância do minério de ferro, em torno de 1,6 toneladas de minério de ferro são necessárias para se produzir 1,0 tonelada de aço. Outros importantes insumos são o carvão e o calcário.

\subsection{Produção de Aço}

A crise mundial iniciada em 2008 atingiu consideravelmente $\mathrm{o}$ setor de mineração e siderurgia no ano de 2009. Tal fato ocasionou uma expressiva retração na produção mundial de aço no período, exceto a China que apresentou elevação de cerca de $14,0 \%$, em relação a 2008. Ainda em 2010, onde era esperada uma prolongação da retração mundial, contudo, ocorreu uma duração menor do que a esperada e foi observado sinais de recuperação na produção industrial global. Sendo considerável o aumento da produção mundial de aço em $2010 \mathrm{em}$ torno de $15,9 \%$ em relação ao ano de 2009.

Em 2011 o Brasil consumiu um total de 45,22 Mtpa (Milhões de toneladas por ano) de concentrado, o que representa cerca de $3 \%$ do total consumido no mundo. A demanda interna é gerada, principalmente, pela produção de aço fabricado por siderúrgicas como CSN, Usiminas, Gerdau e Arcelor Mittal.

\subsection{Oferta de Minério de Ferro}

No mercado transoceânico a China foi a maior importadora de minério de ferro em 2010, sendo a Austrália o seu primeiro fornecedor, com $265 \mathrm{Mtpa}$, seguida pelo Brasil, com 130,9 Mtpa, e em terceiro veio à Índia com 96,8 Mtpa exportadas. O consumo chinês em 2010 foi abastecido em cerca de $70 \%$ de sua demanda pela importação.

Já em 2011, este consumo representou $54 \%$ do total produzido no mundo (952 Mtpa de concentrado em 2011). Os principais fornecedores do gigante asiático foram a Austrália (43\%), Brasil (21\%), Índia (11\%) e África do Sul (5\%). Além da China, países como Japão, Coréia do Sul, Alemanha e França, são grandes dependentes de importação do minério de ferro.

Ainda em 2011, nos mercados transoceânicos o consumo mundial dos concentrados Fines, Pellet e Lump foi 1,1 bilhões, 431 milhões e 227 milhões, respectivamente. Mesmo com o prolongamento da crise europeia e a redução do crescimento chinês para a casa de um dígito ao ano, a demanda por minério de ferro subiu impulsionada pelo crescimento de $7,5 \%$ da produção mundial de aço bruto contra o ano de 2010.

Nos próximos anos, o consumo de minério de ferro deve permanecer elevado em relação a níveis históricos, devido à projeção de crescimento médio de 4,0\% ao ano da produção chinesa de aço. Vale lembrar que a China vive um momento de forte urbanização, com intenso êxodo de sua população das áreas rurais para as cidades. Este deslocamento leva a um significativo aumento de investimentos em infraestrutura e industrialização do país, que em poucas palavras, são processos de alto consumo de aço. 


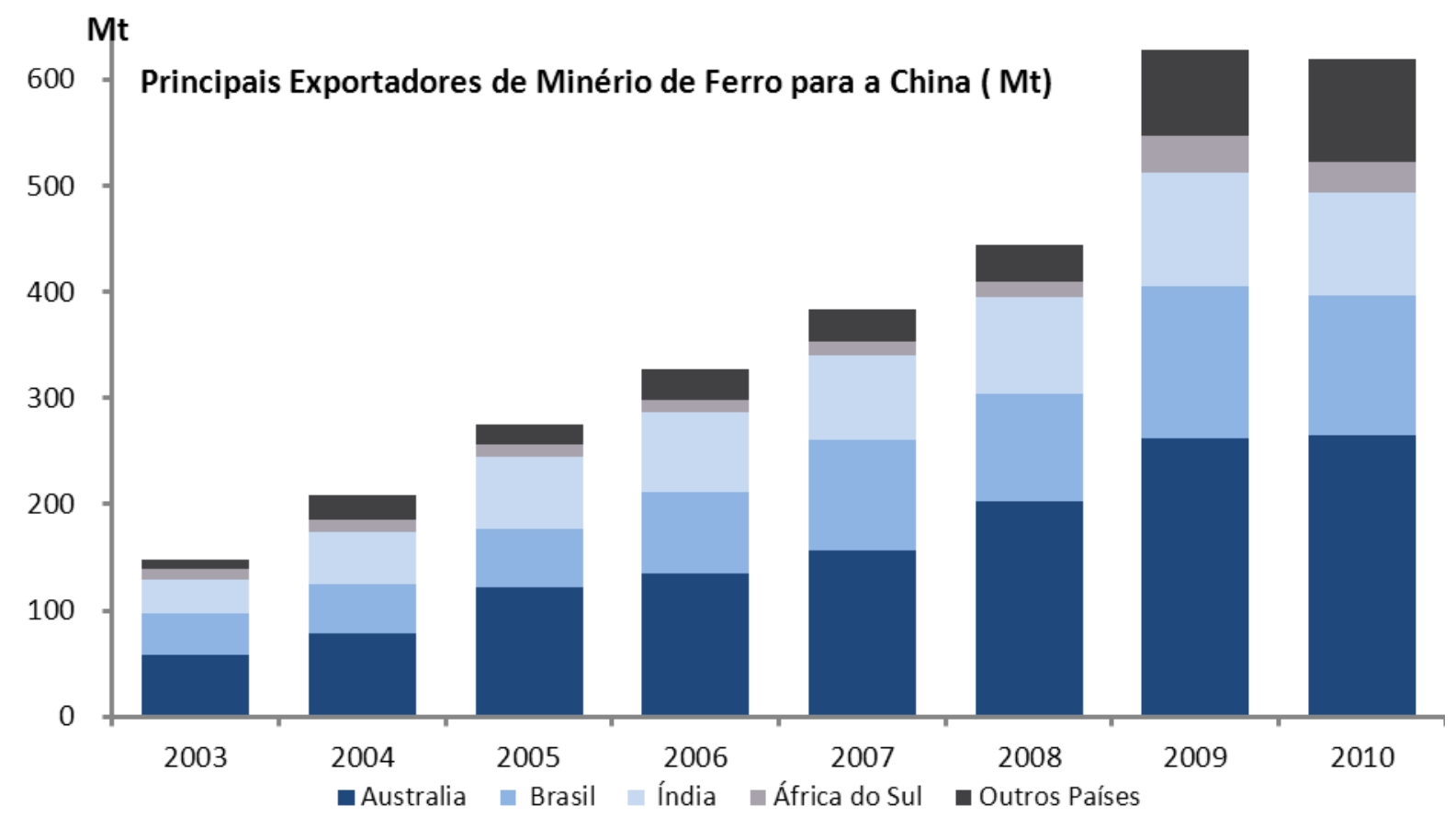

Figura 2- Importação chinesa de minério de ferro por país.

Fonte: Barclays Research, 2012

\subsection{Preços}

O Brasil é o segundo maior fornecedor de minério de ferro do mundo. Em 2011, produziu 243,5 Mtpa de Fines e somente $11 \%$ desse total foi destinado para o consumo interno. A produção do concentrado do tipo Pellet foi 58,81 milhões, sendo $5 \%$ voltado para o mercado interno.

Embora a China seja um dos principais produtores de minério de ferro, com uma produção acima dos $300 \mathrm{Mtpa}$, o tipo de minério encontrado em seu território possui uma recuperação em massa inferior a média de outras minas pelo mundo. Isso significa que é necessário maior aporte de recursos para a implantação de novos projetos, além de implicar em um alto custo operacional uma vez que será necessária a remoção maior de ROM (Run of Mine) para a obtenção do produto final com a esperada concentração padrão $(62 \% \mathrm{Fe})$. Outro fato que também dificulta a redução dos custos chineses é de que sua indústria de mineração está bastante fragmentada, sem a presença de um forte player nacional. Atualmente existem em operação 4.500 minas de minério de ferro.

Segundo relatório do Barclays, no longo prazo, é esperada a redução da Produção Chinesa entre os anos de 2013 a 2021 de quase $3,0 \%$ ao ano $(302,1$ ante 239,5 Mt). Embora a China venha investindo de forma intensa em novos projetos de minério de ferro nos últimos anos, não acreditamos que o preço do minério de ferro na modalidade FOB fique abaixo de US\$120,00/ton, uma vez que abaixo deste número, aproximadamente $20 \%$ das mineradoras locais teriam que parar a sua produção, pois seu custo operacional seria superior ao valor no mercado à vista.

Ainda na questão do preço do minério de ferro, em 2011, a média de preço do minério de ferro $(62 \% \mathrm{Fe})$ na modalidade CIF foi US\$ $175,00 /$ ton, o que representa um aumento de $16 \%$ em relação ao ano de 2010. Esse crescimento foi impulsionado, principalmente, pela maior demanda da China e pela forte redução das exportações indianas para o mercado transoceânico. 


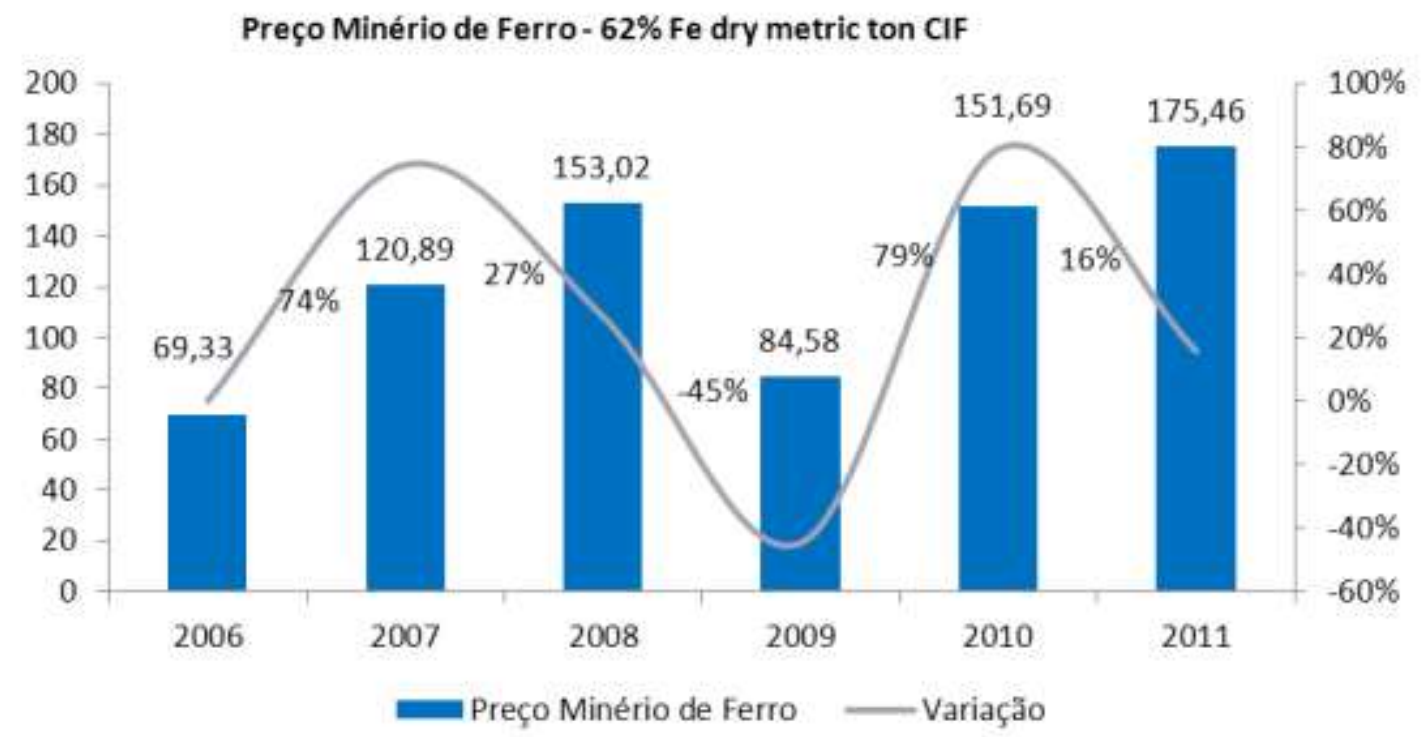

Figura 3 - Preço Minério de Ferro (US\$/ton) teor - 62\%Fe.

Fonte: Bloomberg. 2012

No que se refere às novas descobertas de reservas de minério de ferro, o que é observado é de que existem novos projetos com concentrações cada vez mais baixas de teor férrico e de locais que são de difícil acesso, que elevam o custo de infraestrutura dos mesmos e dificulta sua viabilidade econômica.

Outro fato que merece ser destacado é de que o minério de ferro não tem um substituto forte no mercado. Atualmente, com o reaproveitamento do aço via reciclagem em torno de $80 \%$, a sucata, é o principal produto substituto para $\mathrm{o}$ minério de ferro. Com menor importância, outros materiais mais leves como o alumínio, concreto, madeira e plásticos podem ser considerados substitutos em certos cenários.

\section{APLICAÇÃO DO ESTUDO DE CASO}

Será analisado o valor da viabilidade que os investidores possuem em adiar o inicio do projeto, além de uma opção de expandir a capacidade a capacidade da planta de beneficiamento do minério de 10 Mtpa para 15 Mtpa. Para este cenário, será necessário a premissa que a decisão só pode ser feita daqui a cinco anos, devido à necessidade de estudos de
Engenharia Básica e Conceitual, além da obtenção das licenças ambientais composta basicamente por: Licença Prévia (LP), Licença de Instalação (LI), e por fim a Licença de Operação (LO).

Segundo relatório do Banco Brasil Plural, a estimativa atual de obtenção das licenças está em torno de 540 dias (1,5 anos).

\subsection{Premissas}

As premissas assumidas seguem valores disponibilizados por valores médios de mercado, para novos projetos de minério de ferro que devem entrar em operação até o ano de 2020. Ou seja, foi considerado o tempo de obtenção das licenças, do desenvolvimento da Mina (planta de beneficiamento e infraestrutura), que somaram no total 4 anos. Também foi considerado que os custos de produção (OPEX) serão mantidos constantes ao longo da vida útil do projeto, e que o projeto terá uma curva de aprendizagem (start-up) de dois anos até atingir sua capacidade plena, conforme Tabela 1, a seguir. Por fim, foi considerado que o último ano será o período de exaustão da mina, onde a 
produção será menor além da necessidade

de medidas para o fechamento da mesma.

Tabela 1 - Receita Bruta

\begin{tabular}{|l|c|}
\hline \multicolumn{1}{|c|}{ Premissas } & Valores \\
\hline Vida Útil da Mina (anos) - Em Plena Capacidade & 20 \\
\hline Vida Útil Total da Mina (anos) & 27 \\
\hline Capacidade Anual (Mtpa) & 10 \\
\hline Recursos (Mt) & 200 \\
\hline Início de Produção & 2017 \\
\hline Preço do Minério de Ferro FOB (US\$/ton) & 90,0 \\
\hline Depreciação (\% a.a.) & $10 \%$ \\
\hline Royalties (CFEM) & $4 \%$ \\
\hline Custo Operacional (OPEX) - (US\$/ton) & 50,0 \\
\hline Investimentos Correntes / Sustaining Capital Expenses (US\$/ton) & 1,8 \\
\hline Imposto de Renda (\%) & $34 \%$ \\
\hline Investimento (CAPEX) - (US\$/ton) & 155 \\
\hline
\end{tabular}

Fonte: Autores e Goldman Sachs, 2012

A planta de beneficiamento da mina foi projetada para 20 Mtpa com início de produção a partir de 2017. Por ser um projeto greenfield (novo) foram assumidas como premissas que no primeiro ano de produção será produzido $25 \%$ da capacidade total, $50 \%$ no período seguinte e nos demais anos, a plena expansão em $100 \%$. Como nos projetos existe o fator de exaustão da mina, no último ano serão extraídos $25 \%$ da capacidade atual.

Para o investimento do projeto (CAPEX) foram assumidos múltiplos encontrados no relatório do Goldman Sachs esperados para novos projetos. Valor encontrado é a multiplicação do Investimento (CAPEX) - (US\$/Ton) $\mathrm{x}$ Capacidade Anual. Adicionalmente, projetos de mineração também necessitam de investimentos ao longo de sua vida útil para manter suas operações. Tais aportes são considerados investimentos correntes, ou Sustaining Capital Expenses estimados em US\$ 1,80/ton por minério extraído.

Por fim, após a apresentação dos inputs do modelo, os investimentos necessários para a operação, são necessários estimar as receitas e os fluxos operacionais do projeto.

Nos últimos três anos, o setor apresentou uma nova era em relação aos mecanismos de preço, depois que as negociações de 2009 abandonaram o padrão de contratos anuais. A modalidade vigorou por cerca de 40 anos, e ficou conhecida como benchmark. Em 2010, o setor migrou para um sistema misto com o sistema à vista (spot), mais sensível ao quadro de oferta e demanda, e aos contratos trimestrais que são fechados de acordo com os últimos três meses anteriores do mercado spot. 
Esta afirmação do valor do preço do minério de ferro no formato CIF (Cost, Insurance and Freight), no mercado spot deverá continuar acima de US\$ 140,00/ton nos próximos dois anos e pode ser corroborada pela análise das projeções das principais instituições financeiras que acompanham o mercado de minério de ferro. A conclusão que podemos ter a partir destes valores é de que a cotação deva se estabilizar nos próximos três anos. Além disso, a partir de 2015, é esperada uma redução em virtude do menor crescimento da economia chinesa, principal consumidor desta matéria-prima.

$\mathrm{Na}$ análise do projeto, será usado o valor médio, fornecido por cinco instituições financeiras em seus relatórios correntes. O Teor de ferro assumido para o projeto foi a média, $62 \% \mathrm{Fe}$, ou seja, não houve qualquer prêmio em relação ao mercado. Os preços encontrados estão na modalidade CIF, portanto será necessário trazer o valor para o formato FOB (Free on Board) que não considera valores com frete marítimo e seguros. As projeções destas instituições indicam valor a ser descontado de US\$20,00/ton de minério de ferro transportada.

\subsection{Impostos/Tributos e Taxas}

Foi adotada a legislação vigente considerando o cronograma de atividades de implantação e operação, com seus respectivos fatos geradores.

\subsubsection{CFEM}

A Compensação Financeira pela Exploração de Recursos Minerais (CFEM), estabelecida pela Constituição de 1988, é devida aos Estados, ao Distrito Federal, aos Municípios, e a órgãos da administração direta da União, como contraprestação pela utilização econômica de recursos minerais de seus respectivos territórios.

A CFEM assumida foi de $4 \%$, para o minério de ferro, sobre o faturamento bruto e a alíquota varia de acordo com o produto mineral. A CFEM atual é de $2 \%$ e tem como base de cálculo o faturamento líquido da venda do produto mineral, entendido como o total das vendas menos os tributos incidentes sobre a comercialização, as despesas de transporte e de seguros, mas como o modelo tem por premissa o conservadorismo, foi adotada a provável CFEM que já está em discussão no Congresso Nacional, através do novo Código de Mineração.

\subsubsection{CSSL}

A Contribuição Social Sobre o Lucro (CSSL) é devida ao Governo Federal. Para a sua apuração e recolhimento se aplicam as mesmas regras em conformidade com a legislação em vigor. Sua alíquota é de 9\% sobre o lucro líquido operacional.

\subsubsection{IRPJ}

O Imposto de Renda de Pessoa Jurídica (IRPJ) é um imposto federal, incidente sobre o lucro líquido tributável das empresas, cabendo sua regulamentação, normatização, arrecadação e fiscalização à Secretaria da Receita Federal, órgão vinculado ao Ministério da Fazenda.

O imposto de renda devido é calculado com base na alíquota única de $15 \%$ sobre o lucro líquido tributável, sujeitando-se a parcela do lucro real que exceder a R\$ 60 mil no trimestre à incidência de um imposto adicional, à alíquota de $10 \%$.

\subsubsection{ICMS}

Como o produto será vendido para o mercado externo, o ICMS (Imposto sobre a Circulação de Mercadorias e Serviços) não foi considerado. O crédito de ICMS da fase de construção foi tratado de modo conservador como um custo. Como o produto será exportado, não há acumulação de crédito de ICMS nas vendas. 
Tabela 2 - Modelo do DRE e Fluxo de Caixa Operacional

\begin{tabular}{|l|c|}
\hline \multicolumn{1}{|c|}{ Item (US\$ 000) } & Definnição \\
\hline Produção Anual (Mt) & 10,0 \\
\hline $\begin{array}{l}\text { Preço do Minério de Ferro } \\
\text { (US\$/ton) }\end{array}$ & 90,0 \\
\hline (=) Receita Bruta [US\$ 000] & $\mathbf{9 0 0 . 0 0 0}$ \\
\hline (-) Royalties (CFEM 50\%) & 18.000 \\
\hline (-) Royalties (4\%) & 36.000 \\
\hline $\begin{array}{l}\text { (=) Receita Líquida [US\$ } \\
\text { 000] }\end{array}$ & $\mathbf{8 4 6 . 0 0 0}$ \\
\hline (-) OPEX (US\$/ton) & 48,0 \\
\hline $\begin{array}{l}\text { (=) EBITDA / LAJIDA [US\$ } \\
\text { 000] }\end{array}$ & $\mathbf{3 6 6 . 0 0 0}$ \\
\hline Margem EBITDA (\%) & $\mathbf{4 3 , 3 \%}$ \\
\hline
\end{tabular}

Fonte: Autores e Goldman Sachs, 2012

\subsection{Taxa de Desconto do Projeto}

Para Copeland (2002), o custo de oportunidade relacionado ao financiamento por capital próprio é o de maior dificuldade para se calcular devido ao fato de não poder ser observado no mercado. O modelo mais conhecido e largamente utilizado em finanças para o cálculo do custo de capital próprio é o CAPM - Capital Asset Princing Model. Este modelo foi criado por Jack Treynor (1961), William Sharpe (1964), John Lintner (1965) e Jan Mossin (1966), independentemente, baseado no trabalho de Harry Markowitz (1952) sobre diversificação e teoria moderna de portfólio.

Segundo Ross (2008), o CAPM mostra que o retorno esperado de determinado ativo depende de três fundamentos:

- Valor puro do dinheiro no tempo, este medido pela taxa livre de risco, que mostra a recompensa exigida pela simples espera pela devolução do dinheiro, sem, contudo, assumir qualquer tipo de risco.

- Recompensa por assumir um risco sistemático, sendo medido pelo prêmio por risco de mercado que corresponde à recompensa que o mercado oferece para se assumir um nível médio de risco sistemático.

- E por fim, o nível de risco sistemático, medido pelo Beta, que é o risco não diversificável de um ativo em relação ao seu mercado.

Equação 2 - A equação do custo do capital ordinário:

$$
K_{E}=R_{f}+\beta *\left(R_{m}-R_{f}\right)
$$


Tabela 3 - custo do capital ordinário

\begin{tabular}{|c|l|}
\hline Termo & \multicolumn{1}{|c|}{ Definição } \\
\hline$K_{E}$ & Retorno esperado pelo ativo \\
\hline$R_{f}$ & Retorno de um ativo livre de risco \\
\hline$\beta$ & Risco sistemático ou não-diversificável de um ativo em relação ao mercado \\
\hline$R_{m}$ & Retorno esperado de uma carteira de mercado \\
\hline$\left(R_{m}-R_{f}\right)$ & Prêmio de risco do mercado \\
\hline
\end{tabular}

\subsection{Flexibilidades para um Projeto de Mineração - Minério de ferro.}

$\mathrm{Na}$ área mineral, os projetos têm como característica a alta demanda por investimentos. Estão também sobre o controle da empresa as decisões de interromper suas atividades, expandir a capacidade e início de novas operações. Somam-se a isso, minas então não competitivas podem voltar as suas operações caso o preço do minério de ferro, no mínimo seja igual aos seus Custos Totais Fixos.

O minério de ferro não é uma commodity, uma vez que sua forma de comercialização dependente de características físicas (granulométrica) e químicas (teor de contaminantes e teor de ferro), onde o mercado costuma pagar um prêmio por um produto que contenha maior teor de ferro e menor teor de contaminantes, por exemplo. Com isso, é muito difícil de fazer um hedge para o seu produto, o que torna os projetos suscetíveis à variação do preço do minério de ferro.

Neste estudo de caso, o projeto de minério de ferro possui a opção de ter sua capacidade expandida para o dobro da sua produção projetada a partir do quarto ano, após o início de suas atividades. Por ser um projeto que demanda um volume vultoso de recursos financeiros, assim como o tempo de obtenção das licenças ambientais, a tomada de decisão deverá ser dois anos antes da nova capacidade entrar em produção. Os múltiplos para esta expansão serão o mesmo que os apresentados para o início do projeto.

\section{RESULTADOS}

\subsection{Modelo Básico}

Com uma curva projetada para preço, sem qualquer possibilidade para flexibilização do projeto, foi calculado o VPL de US\$ 41,075 Milhões, considerando uma TMA de $12 \%$. O valor encontrado é o somatório dos Fluxos de Caixa Descontados. A Tabela 4 a seguir apresenta as principais rubricas do projeto, e os valores do DRE e Fluxo de Caixa se encontram em US\$ Milhares, enquanto a Tabela 5 apresenta o Fluxo de Caixa Descontado, ilustrando ainda o vigésimo-sexto ano, onde a Necessidade de Capital é Zerada, como definição de capital de giro. 
Tabela 4 - DRE e Fluxo de Caixa

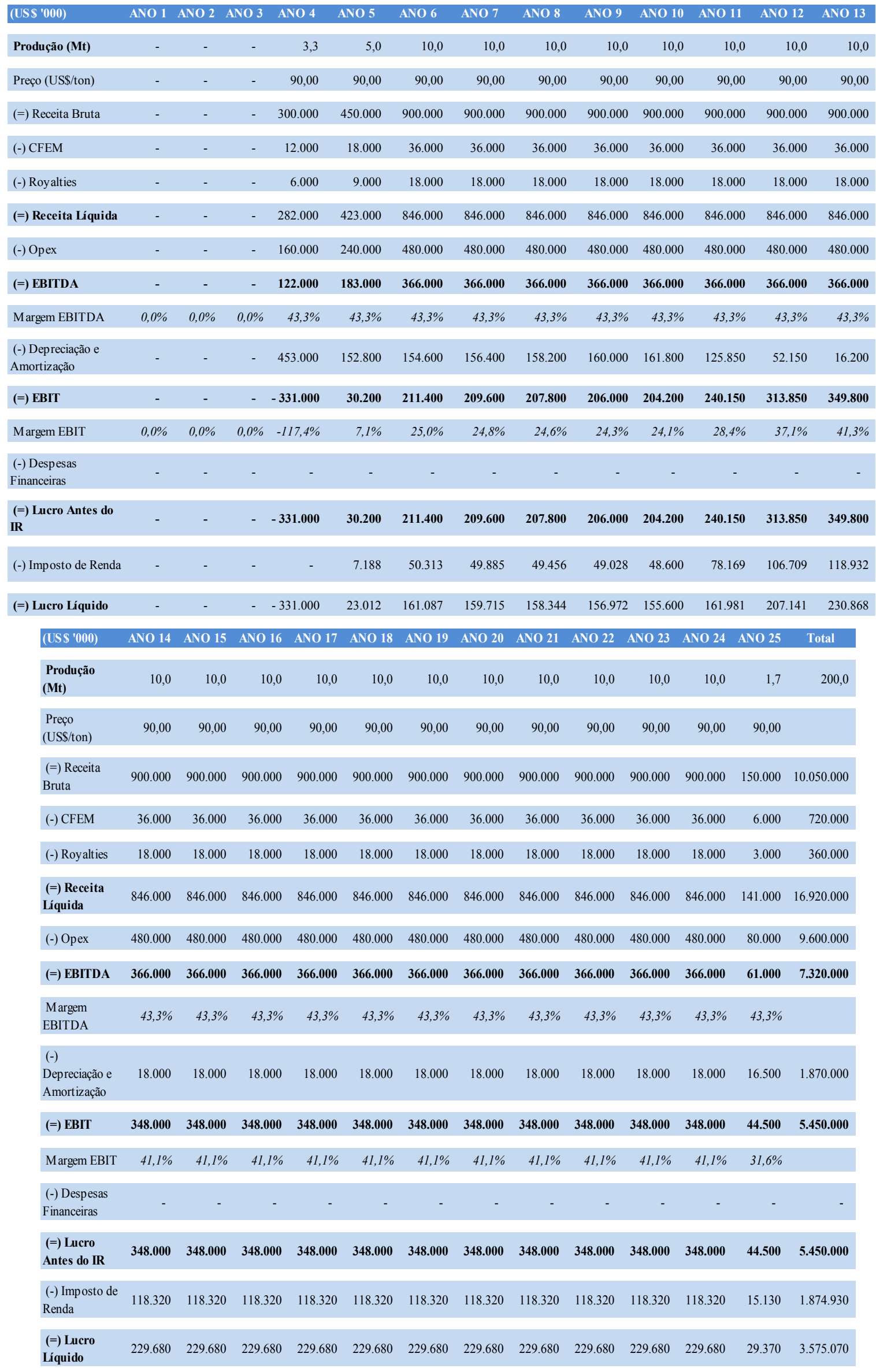


Tabela 5 - Fluxo de Caixa Descontado

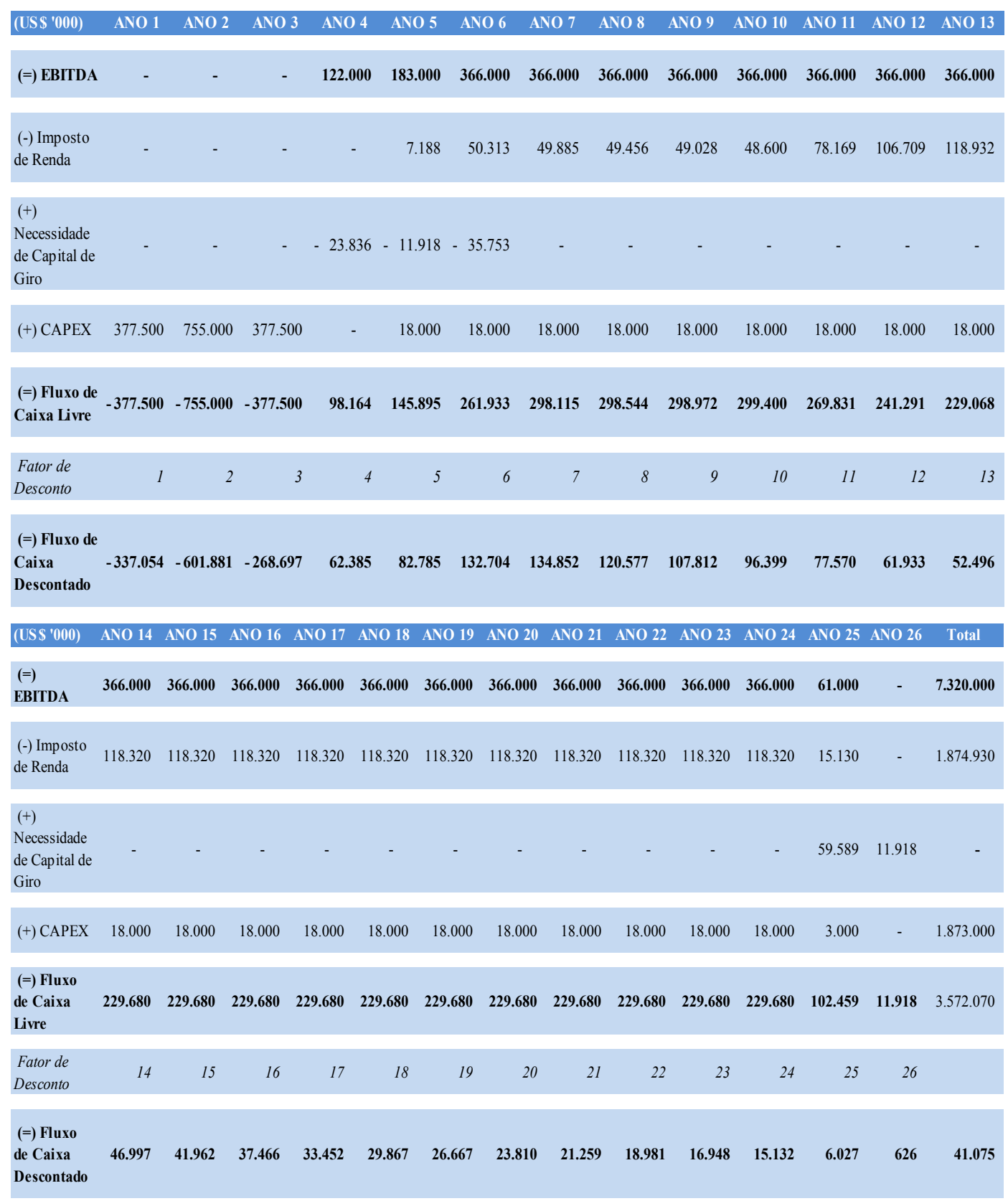

Fonte: Autores

\subsection{Volatilidade}

$\mathrm{O}$ preço do minério de ferro ao longo da vida útil da mina (20 anos) foi utilizado como variável de incerteza, e assumido como premissa para efeito de cálculo. Foi calculado o desvio padrão entre os anos de 1980 - 2010 pelo modelo Platts. Esta volatilidade foi inserida no preço do minério de ferro, com desvio padrão de $20 \%$ e o uso da lognormal, já que o preço não poderá ser considerado como negativo.
Como a modelagem estocástica da única incerteza do projeto já assumida, foi utilizada a simulação de Monte Carlo, que após 10 mil interações forneceu a distribuição esperada do projeto conforme Figura 4 a seguir, com a média em-US\$ 107,0 milhões. 
Figura 3 - Histograma de dispersão de Resultados (VPL)

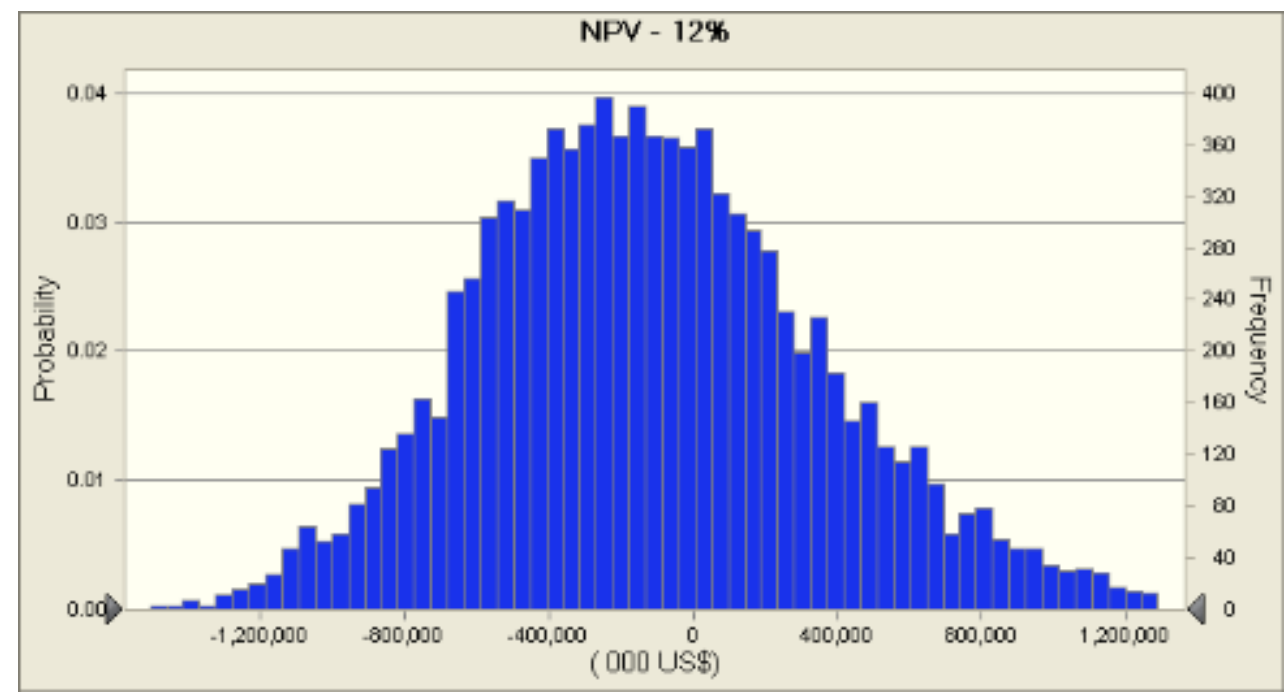

Fonte: Elaborado pelos autores

\section{CONCLUSÃO}

O exercício proposto no presente trabalho permite confirmar que a Teoria das Opções Reais na Avaliação de projetos de Mineração leva a melhor atribuição de valor ao projeto.

A partir do presente estudo concluiu-se que o valor, caso seja considerada a opção de expansão do projeto, uma nova fase do projeto (Fase Expansão) se torna menos atrativa.

O resultado sugere a importância do uso da Teoria das Opções Reais na avaliação de projetos. Para trabalhos futuros sugere-se simulação em outros projetos de mineração tais como rocha fosfática, que podem resultar em mais de um tipo de produto. Poderia se utilizar opções tais como: parada temporária, abandono do projeto ou múltipla.

\section{7 \\ BIBLIOGRÁFICAS}

BORDEAUX-RÊGO, R.; PAULO, G. P.; SPRITZER, I. M. de P. A.; ZOTES, L. P. 2009.Viabilidade econômico-financeira de projetos. $2^{a}$. ed. Rio de Janeiro: Editora FGV.

BRANDÃO, L. E.T. e DYER, J. S. 2005. Decision analysis and real options: a discrete time approach to real option valuation. Annals of Operations Research, V. 135, Issue 1, p. 21-39.

BRANDÃO, L. E.T, Bastian Pinto, C.,Lima Gomes, L., Schuabb Salgado, M. fev. 2012. Incentivos Governamentais em PPP, uma análise por opções reais. ERARevista de Administração de Empresas v.52 n 1, pp. 10-33,

BRAGA, J. M., SEIDL, P., LONGO, W. P.2009."Análise Da Viabilidade Econômica Da Integração De Células A Combustível Nas Plantas De Cloro-Soda Para Utilização Do Hidrogênio Gerado No Processo". ENGEVISTA, Vol.11, No.1.

COPELAND, Tom; KOLLER, Tim; MURRIN, Jack. 2002. Avaliação de empresas - Valuation: Calculando e gerenciando o valor das empresas. 3. ed. São Paulo: Makron Books Ltda.

COPELAND, TOM; ANTIKAROV, VLADIMIR. 2001. Opções Reais: um novo paradigma para reinventar a avaliação de investimentos. Editora Campus, Rio de Janeiro.

DAMODARAN, ASWATH. 1999. Estimating Risk Parameters. Working 
Paper. Stern School of Business, New York.

DAMODARAN, ASWATH. 2002. Investment Valuation: Tools and Techniques for Determining the Value of Any Asset. New York: John Wiley \& Sons, Inc., second edition.

GRAHAM, J.R. and HARVEY, C.R. (2001), "How do CFOs make capital budgeting and capital structure decisions?", The Journal of Applied Corporate Finance Vol. 15, No. 1, 2002.

GRAHAM, J. R.; HARVEY, C. R. 2001. The theory and practice of corporate finance: evidence from the field. Journal of Financial Economics, v.60, p. 187-243.

LEAL, Ricardo. P.2002. Revisão da literatura sobre estimativa do custo de capital aplicada ao Brasil, Coppead, UFRJ, mimeo.

NEPOMUCENO, F. 1997. Tomada de decisão em projetos de risco na exploração de petróleo.Tese de Doutorado,Unicamp/IG/DARM.

Relatório disponível em WWW.BLOOMBERG.COM acesso em $28 / 12 / 2012$

Relatório disponível em http://minerals.usgs.gov/minerals/pubs/co mmodity/iron_ore/ acesso em 26/12/2012

Relatório disponível em www.ibram.org.br/sites/1300/1382/00001 669.pdf acesso em 29/12/2012

RUDENNO, VICTOR. 2012. The Mining Valuation Handbook: Mining and Energy Valuation for Investors and Management. John Wiley \& Sons, Autralia.
TRIGEORGIS, Lenos. 1993. The nature of option interaction and the valuation of investments with multiple real options. Journal of Financial and Quantitative Analysis, 28(1):0.

Vale, Henrique Vasquez Féteira do. 2012. Orçamentação, Custo E Estrutura De Capital: Teoria E Prática No Brasil. Dissertação de Mestrado, Departamento de Engenharia de Produção, Universidade Federal Fluminense.

WOMACK, Kiplan Shea. 2012. An Empirical Approach to Measuring Real Options Embedded within Urban Land Values: A Collection of Essays, Doctor Dissertation. Graduate Faculty of The University of Georgia. 